\title{
UMA EUROPA INVENTADA PELO FUTEBOL
}

\author{
AN EUROPE INVENTED BY FOOTBALL \\ UNA EUROPA INVENTADA POR EL FÚTBOL
}

Alexandre Fernandez Vaz*

\section{Palavras chave}

Futebol.

Europa.

História do Século XX.

\section{Keywords:}

Football.

Europe.

History, 20th

Century.

Palabras clave:

Fútbol.

Europa.

Historia del Siglo

XX.
Resumo: O presente ensaio procura desenvolver uma sugestão de Detlev Claussen, a de que uma ideia de Europa se forma com o futebol. Para tanto, recorre a diferentes posições de teóricos e literatos europeus sobre esse esporte, cruzando-as nos termos de sua materialização em torno das origens das copas europeias e da circulação de jogadores e formas de jogo. Argumenta, neste sentido, por uma constituição continental por meio de um elemento cultural popular e que concorre com as narrativas tradicionais.

Abstract: This essay elaborates on Detlev Claussen's original view that an idea of Europe is formed by football. It resorts to various views by European theorists and scholars on football and analyzes them in the context of the origins of European Football Cups and the circulation of players and playing styles. Then it points to continental constitution through a popular cultural element that dissents from traditional narratives.

Resumen: El presente ensayo pretende desarrollar una sugerencia de Detlev Claussen, según la cual una idea de Europa se forma con el fútbol. Para ello, recurre a diferentes posturas de teóricos y literatos europeos sobre ese deporte, cruzándolas en términos de su materialización en torno a los orígenes de las copas europeas y de la circulación de jugadores y formas de juego. Argumenta, en este sentido, por una constitución continental por medio de un elemento cultural popular y que concurre con las narrativas tradicionales.
* Universidade Federal de Santa Catarina. Florianópolis, SC, Brasil. E-mail: alexfvaz@uol.com.br

Recebido em: 24/08/2017 Aprovado em: 26/11/2018

DOI: https://doi.org/10.22456/1982-8918.75919 (c) (i) () Licence 


\section{INTRODUÇÃO}

Em 1953, no contexto da reconstrução alemã do pós-guerra, e quando não apenas a Europa, mas o mundo, se reconfigurava nos termos do que veio a se chamar Guerra Fria, Thomas Mann (1974) profere um tão importante quanto lindo discurso para estudantes universitários em Hamburgo. Evocando reminiscências de sua infância e juventude, fala da felicidade em respirar novamente 0 ar hanseático, mesmo que não o da querida Lübeck, onde nascera, e de poder conviver no idioma de sua infância, experiência marcante desde que voltara do exílio nos Estados Unidos.

Destacando a generosidade e o ambiente agradável que pudera desfrutar na América, o grande escritor sentira-se, por paradoxal que pareça, mais e mais europeu no exílio. É curioso que ele não observe que tenha visto a si mesmo mais alemão ou germânico em terras americanas, mas cada vez mais europeu. Preocupado com a bipartição da Alemanha, Mann (1974) predica a reunificação do país, mas adverte sobre o perigo de seu senhorio em relação à Europa. Parafraseando Goethe, exorta que não se tenha medo de que os tempos vindouros tragam uma Europa unida sem que uma Alemanha unificada esteja em seu centro e liderança. Prefere seu país servindo à autodeterminada Europa.

Um ano depois do discurso de Mann, a Alemanha fraturada viveria uma de suas derradeiras experiências culturais como não dividida, antes da reunificação de 1990 - na verdade, anexação da parte oriental pela República Federal. Em Berna, Suíça, pela última vez um único selecionado alemão de futebol disputou e venceu uma Copa do Mundo, infligindo uma duríssima vitória por 3x2 à seleção da Hungria, equipe que encantara a todos com suas inovações táticas e variações de jogo. Na voz do locutor Herbert Zimmermann, como registra Detlev Claussen (1998), os alemães puderam escutar pelo rádio a grande final, cujo resultado surpreendente fez valer o primeiro título mundial de futebol para o país e o epíteto de "Milagre de Berna" para aquela partida.

Vinte anos depois, a Alemanha encontrou-se cindida em um campo de futebol, desta vez na mesma Hamburgo do discurso de Mann, em partida pela Copa realizada na Alemanha Ocidental. Desta vez a favorita República Federal foi surpreendentemente derrotada pela República Democrática. Claussen (1997) conta que foi a primeira e última vez que presenciaria, em um estádio, a unanimidade quanto à justeza de um resultado. Claramente, a derrota fora merecida, a equipe campeã europeia de 1972 envelhecera, Günter Netzer, que era, por seu estilo de jogo, ídolo da Nova Esquerda, fizera péssima partida. A sorte voltaria a sorrir para os alemães ocidentais na partida final contra a seleção da Holanda, de Johan Cruyff e Rinus Michels, derrotada depois de seguidamente derrubar os campeões mundiais sul-americanos, Uruguai, havia muito, e Brasil, então detentor do título, com contundentes placares, não sem também golear a seleção argentina, seleção que venceria o Mundial seguinte - jogando a final, aliás, contra a própria Holanda.

Não foi a única contenda entre os estados alemães separados. Foram muitas e importantes as partidas entre clubes em noites de quarta-feira, pela Copa dos Campeões da Europa, torneio hoje chamado de Liga dos Campeões. Em 1986, por exemplo, aconteceu 0 jogo que seria considerado pela importante revista 11 Freunde - a partir de uma enquete com jornalistas, treinadores e jogadores -, talvez com algum exagero, o mais importante de todos 
os tempos. Pelas quartas de final, jogaram Bayer Uerdingen ${ }^{1}$ e Dynamo ${ }^{2}$ Dresden, em Krefeld, Alemanha Ocidental. $O$ jogo de ida fora vencido pelos alemães orientais, jogando em casa, por $2 \times 0$, e o primeiro tempo da partida de volta terminara em $3 \times 1$ para os visitantes. Eis que nos trinta minutos finais, o Bayer faz seis gols, virando o placar para $7 \times 3$, classificando-se para a etapa seguinte e configurando o "Milagre de Grotemburg" (nome do estádio de Krefeld). Após a partida, o goleiro do Dynamo driblaria os oficiais da Stasi, o Ministério para a Segurança do Estado (Ministerium für Staatssicherheit) da Alemanha Oriental, presente junto à delegação, e abandonaria o hotel de concentração, refugiando-se desse lado da fronteira. 0 jogo da "Química do Oeste contra a Física do Leste"3, como o chamou um jornal, marcou mais uma cartada no curso da Guerra Fria, já que o jogador foi denunciado como traidor e mercenário pela imprensa de seu país. $O$ episódio também expressa toda a tensão, via futebol, de um mundo que, naquele momento, separava a Alemanha. A Copa da Europa, de alguma maneira, e talvez pelo seu lado perverso (pelo verso), o fez novamente encontrar-se.

As três situações futebolísticas exemplares dramatizam a separação da Alemanha, aquela tão indesejada por Thomas Mann e que encontrou seu fim há 27 anos. Elas expressam sentimentos e mal-estares de um país que demorou a unificar-se para logo ser dividido em dois, embaralhando as pretensões e crenças na figura do estado nacional. Mas Mann estava preocupado especialmente com uma cultura europeia. Tentemos ver, então, como o futebol pode ter contribuído para a geração e consolidação de uma ideia de Europa.

Para desenvolver essa questão, opero neste texto com uma hipótese proposta por Detlev Claussen (2014a, s.p.), segundo a qual "[...] a Europa começa em uma noite de quarta-feira". Para desenvolvê-la, trago algumas situações exemplares que ajudam a pensá-la nos termos do nosso tempo e seus desafios. Antes, porém, faço um breve passeio apresentando como o futebol vem sendo entendido por intelectuais dedicados a pensar a Europa como questão, outros mais atentos ao futebol como fenômeno central ou periférico em suas análises, havendo ainda os que sintetizaram uma e outro no mesmo esforço. Ao final, apresento algumas linhas e consequências que nos convidam a pensar levando em conta a invenção do futebol como cultura das classes trabalhadoras no short century, o breve século vinte que teria começado com a I Guerra Mundial e findado com a derrocada do Socialismo Realmente Existente (HOBSBAWM, 1997), movimento que ao mesmo tempo reforça e pondera o nacionalismo (HOBSBAWM, 2007). Trata-se de questão das mais importantes, segundo penso, se considerarmos a força de coesão da cultura popular urbana no espírito europeu, e como esse fenômeno cultural pôde ajudar a inventar uma tradição (HOBSBAWM, 1983), qual seja, a Europa como pertencimento e projeto.

\section{INTELECTUAIS EUROPEUS, FUTEBOL}

Não é unânime o prestígio do futebol entre intelectuais europeus. O esporte em geral, o futebol às vezes em primeiro plano, recebe pelo menos dois tipos de crítica, uma relacionada

\footnotetext{
1 Hoje, depois do fim do patrocínio do grande holding de produtos químicos Krefelder Fußball-Club Uerdingen 05 e.V.

2 Destaque-se aqui o quanto o esporte, em particular na experiência do Socialismo tal como existiu, guarda forte afinidade com certo tipo de ideologia do progresso e com o fetiche pelo trabalho, com as pretensões de domínio da natureza. Exemplar neste sentido é a origem dos clubes esportivos da República Democrática, fortemente vinculada, principalmente, a ramos da indústria e dos serviços da "Nova Sociedade", tais como Fortschritt, Aufbau, Lokomotive, Medizin, Post, que deveriam fazer um contraponto com as novas associações e o espírito esportivo "reacionários" do Oeste (KLUGE, 2004).

3 Disponível em: <http://www.taz.de/!5285529/>. Acesso em: 20 mar. 2016; Disponível em: <http://www.11freunde.de/artikel/wolfgang-funkelueber-das-wunder-von-der-grotenburg>. Acesso em: 20 mar. 2016.
} 
ao domínio excessivo do corpo e à sua correspondente destruição como esfera de gratificação pulsional, produzindo sofrimento correspondente com a construção de uma subjetividade vinculada à exploração no trabalho; outra - aparentada com a primeira - que o vê como espetáculo vinculado à dominação subjetiva via esfera do entretenimento. Dois dos grandes representantes dessas críticas são Umberto Eco e Theodor W. Adorno.

Para Eco (2015), o futebol se apresentaria como expressão de irrealidade, espetáculo de ficção a substituir a política, tanto porque o conhecimento demandado para ele não seria tão vasto quanto se diz, quanto porque cada um estaria dispensado da ação sobre o fenômeno, 0 próprio jogo. Como em uma brincadeira de crianças, o futebol tornaria possível, portanto, jogar com a esfera pública sem se responsabilizar por ela. 0 esporte não se materializaria, senão como pura dramatização, e com atores mais capazes que os profissionais, para desempenhar o próprio papel. Os espectadores teriam com ele, então, uma relação voyeurística.

Diz o ensaísta, semiólogo e romancista italiano:

Debo aclarar ahora que, en realidad, no tengo nada en contra de la pasión futbolística. Al contrario, la apruebo y la considero providencial. Esas multitudes de hinchas apasionados y segados por el infarto en las graderías, esos árbitros que pagan un domingo de celebridad exponiendo su persona a graves injurias, esos excursionistas que descienden ensangrentados del autocar, heridos por los vidrios rotos a pedradas, esos festivos mozuelos que, borrachos, recorren por la tarde las calle, asomando su bandera por la ventanilla de utilitario sobrecargado y se estrellan contra un TIR, esos atletas destruidos psíquicamente por lacerantes abstinencias sexuales, esas familias arruinadas económicamente por ceder a insanas reventas en el mercado negro, esos entusiastas cegados por el estallido de un petardo celebratorio me llena de alegría el corazón. Soy tan partidario de la pasión futbolística como lo soy de las carreras, de las competiciones motociclistas al borde de los precipicios, del paracaidismo desatinado, del alpinismo místico, de la travesía de los océanos en botes de goma, de la ruleta rusa y del uso de droga (ECO, 2015, p. 243-244).

Em lugar da prática do esporte - que teria, esta sim, suas virtudes - predominaria 0 falatório sobre ele, ou já não mais, e sim sobre o que a imprensa diz sobre o futebol. Este, por sua vez, faria parte, finalmente, do circo contemporâneo, cuja função é, como sempre, ocupar e divertir as massas, de modo que elas - e de resto, tudo - se mantenham onde estão.

Em entrevista ao L'Unita em 1982, às vésperas da Copa do Mundo na Espanha, Eco relacionava o futebol ao nacionalismo:

O ideal olímpico, de fato, parece querer irmanar as pessoas. O futebol, nem mesmo em sonho. [...] Porque fomenta o nacionalismo muito estúpido. E no nacionalismo, se você se observa, há sempre um alto coeficiente voyeurístico: Malta, Malvina, Córsega, é fatal... As pessoas se deslumbram com figuras míticas, delegando a outros suas decisões e ações" (ECO, 1982, s.p.). ${ }^{4}$

Por outro lado, divertir é uma espécie de bálsamo legitimador do sofrimento, lemos nos fragmentos filosóficos do clássico livro Dialética do esclarecimento, de Max Horkheimer e Theodor W. Adorno (1997). Ou ainda, como Adorno (1992) escreve em suas Minima Moralia,

4 Uma posição bastante semelhante à de Eco é a de Robert Redeker (2016), para o qual o esporte exerceria o domínio temático da mídia, em detrimento de outros assuntos vistos como mais sérios, e, com isso, teria predominância em todo tipo de conversação diária. A dependência das massas em relação ao esporte seria de tal ordem que nem mesmo o conceito de alienação (Entfremdung), oriundo da crítica à economia política, seria suficiente. Para ele seria mais efetivo o de poder espiritual, tal a totalização do esporte e de seus valores para a sociedade, em especial em seu caráter de legitimação da ficção alicerçada na ciranda do capital financeiro, demarcado pela inutilidade produtiva de jogadores comercializados o tempo todo - e sobre os quais não se para de falar. Uma resposta a Redeker, discordando, sobretudo, dos critérios que ele empregou em sua crítica ao esporte, foi feita por Gumbrecht (2016). 
"É com o sofrimento dos homens que se deve ser solidário: o menor passo no sentido de divertilos é um passo para enrijecer o sofrimento" (p. 20). Para Adorno, o esporte em sua versão de espetáculo é expressão do coletivismo e da diluição do sujeito quando o indivíduo vocifera nos estádios, e promotor da dor e do sofrimento quando o corpo é submetido ao martírio das exigências do rendimento. Na continuação, jamais publicada enquanto viveu, do capítulo sobre indústria cultural de Dialética do esclarecimento, chamado 0 esquema da cultura de massas, Adorno não deixa por menos:

Os recordes, nos quais os esportes encontram sua realização, proclamam 0 evidente direito dos mais fortes, que emerge tão obviamente da concorrência, porque ela cada vez mais os domina. No triunfo de tal espírito prático, tão longe das necessidades de manutenção da vida, o esporte se torna uma pseudopráxis, na qual os praticantes não mais podem agir por si mesmos, mas mais uma vez se transformam em objetos, o que, na verdade, já são. Em sua literalidade sem brilho, destinada a uma gravidade [seriedade] brutal, que entorpece cada gesto do jogo, torna-se o esporte o reflexo sem cor da vida endurecida e indiferente. Só em casos extremos, que deformam a si mesmo, o esporte mantém o prazer do movimento, a procura pela libertação do corpo, a suspensão das finalidades (ADORNO, 1997a, p. 329).

Ou ainda, em uma das poucas vezes em que se referiu ao futebol, em um breve ensaio sugestivamente chamado Opinião, loucura e sociedade:

A força do tabu sobre o narcisismo individual, sua repressão, contudo, leva ao nacionalismo o pernicioso poder. Na vida dos coletivos as coisas acontecem diferente do que rege as relações entre os indivíduos. Já em cada partida de futebol a população local se alegra maltratando, sem envergonhar seu próprio time, os adversários; a atualmente não tão bem aceita en canaille, como a tratou Anatole France, constata na 'Ilha dos Pinguins' que cada pátria deve estar acima de tudo no mundo ('über alles in der Welt' - referência ao hino alemão antes da II Guerra - afv). Basta aceitar seriamente as normas da vida privada burguesa para ter sucesso na sociedade. Mas uma tal bem-intencionada recomendação ignora o impedimento, que chegará sob condições, imposto aos indivíduos, que frustrará tão constantemente seu narcisismo individual, amaldiçoando-o a tal impotência que o condenará ao narcisismo coletivo (ADORNO, 1997b, p. 589).

\section{NO FUTEBOL, O MOVIMENTO DA COTRADIÇÃO}

Teriam razão Eco e Adorno, dois pensadores tão diferentes entre si, mas tão europeus, ambos brilhantes e desde crianças notadamente avessos ao esporte? Sim e não. O esporte, o futebol particularmente, é mesmo esse fenômeno que ambos descreveram com acuidade e com o ferrão da crítica do presente, mas é também algo mais que eles não puderam ver.

Ao ser perguntado, certa vez, por que a Teoria Crítica da Sociedade deveria se ocupar do futebol, Claussen (2014b) respondeu, na boa e velha tradição dialética, que a sociedade nele se deixa ver:

Adorno disse que a sociedade burguesa se deixa conhecer em uma sinfonia de Beethoven. Exatamente da mesma forma se pode conhecer a sociedade atual por meio do futebol. Para que se possa ter chances de vitória na Champions League, é preciso combinar diferentes jogadores de todo o mundo. 0 mesmo ocorre com a seleção nacional: até poucos anos, Alemanha e Áustria apresentavam equipes etnicamente de uma só tonalidade, enquanto hoje a variação é enorme. A diversidade social está também nesses selecionados (CLAUSSEN, 2014b, s.p.). 
Em outra ocasião, desta vez polemizando com uma afirmação de Oskar Negt, Claussen prosseguiu:

Sem a análise do jogo, a teorização sobre a sociedade regride a um pessimismo cultural que vêa competição entre nações como meramente uma guerra sem armas, e denuncia o processo de comercialização do futebol como operação demoníaca a serviço da destruição da sociedade. Simplesmente depreciar a comercialização é rebaixar a crítica da indústria cultural a uma forma de ressentimento contra as excitações baratas, prática comum entre intelectuais que, como Oskar, caçoam das pessoas que querem se divertir ao invés de se ocuparem das coisas sérias da alta cultura. Esse movimento é um subproduto do preconceito do burguês instruído contra os english sports (CLAUSSEN, 2012, s.p.).

Tal análise Claussen (2014c) faz em seu livro sobre Béla Guttmann, não exatamente a biografia, menos ainda a hagiografia de um treinador, muito mais a história do século vinte interpretada pelo futebol em seu desenvolvimento globalizado, dentro e fora do campo. 0 técnico húngaro, um europeu antes de tudo, que compôs a comissão técnica do time vicecampeão mundial em 1954, teria sido o primeiro caso de globalização no futebol, duas vezes seguidas vencedor da Copa dos Campeões da Europa pelo português Benfica, mas também com trabalhos na Itália, na Áustria, assim como nos Estados Unidos, Uruguai, Argentina e Brasil. Guttmann foi campeão paulista com o São Paulo, em 1957, e introduziu entre nós o sistema WM, empregado no ano seguinte pela seleção brasileira que da Suécia trouxe a primeira Copa para o país. Dissolução do Império Austro-húngaro, diáspora judaica, desenvolvimento do esporte como espetáculo para as grandes massas, consolidação do cultivo do corpo como prática, ascensão da classe trabalhadora em nichos aristocráticos e burgueses, tudo isso e mais está na história do futebol, tal como narrada a partir da figura do grande treinador.

O futebol do Danúbio, representado por Guttmann e por tantos astros que foram emergindo a partir de um movimento que fez Budapeste rivalizar com Viena, também se mostrou responsável pela demarcação cultural de comunidades judaicas da Europa Central. Pois é o futebol do Danúbio que seria um dos formadores, como espírito, do momento culminante do calcio italiano, segundo nada mais, nada menos, que Antonio Negri. Em uma entrevista de junho de 2006, o estudioso de Espinoza, teórico da esquerda e das multidões, analista do contemporâneo, mas também fervoroso torcedor do AC Milan, assim se manifesta, explicitando um argumento de sua esposa, francesa e torcedora da Juventus Turim:

\begin{abstract}
A Hungria era uma grande equipe de futebol 'danubiana': um estilo extremamente delicado, de movimento através das linhas, antes que pela força. 0 grande futebol italiano é uma síntese de duas vertentes: 0 futebol do Danúbio e 0 argentino. Os danubianos são as linhas, os argentinos o indivíduo. Daí nasce o que Brera chamava de 'a raça camponesa italiana'. Você coloca esses três elementos juntos e tem a síntese dialética perfeita, a força do futebol italiano (NEGRI, [2006], s.p.).
\end{abstract}

A força de Budapeste, assim como de Praga e de Viena para a formação da Europa é singular. Quem cresceu no pós-guerra nem sempre reconhece que a Hungria, a Áustria e a Bohemia geraram muito do que depois seria reconhecido como Europa, principalmente na virada do século XIX para o XX, fruto, em grande parte, da intelectualidade judaica de vanguarda: Psicanálise, Dodecafonia, mas também um jeito de jogar futebol. ${ }^{5}$

É com razão que Negri ([2006]) se refere também à influência argentina. Não foram poucos os jogadores da margem direita do Rio da Prata que, refazendo ao inverso o caminho

5 Inspiro-me aqui, livremente, em uma resposta que Milan Kundera oferece em entrevista a Philip Roth (2002). 
dos pais, foram à Itália dos anos 1930 em diante, não apenas para participar dos torneios no país, mas também para representar a Squadra Azzurra ${ }^{6}$. Expressão dos processos de globalização em forma do deslocamento de um razoável contingente de trabalhadores, na medida em que o futebol se profissionalizava, as idas e vindas entre Europa e América foram constantes. Com a Espanha não foi muito diferente, Di Stéfano sendo o exemplo mais conhecido. Não se pode pensar o futebol europeu sem a presença da América, seja compondo os quadros dos clubes e seleções, seja fazendo um contraponto ao estilo de jogo, como sugere Pier Paolo Pasolini.

É conhecida a distinção que Pasolini (2005), um amante do futebol que dizia que algumas de suas melhores lembranças eram as tardes de domingo da juventude em que praticava o calcio, faz entre os modelos de prosa e de poesia do esporte. Para o cineasta, escritor e filósofo, pelo menos desde que Roberto Esposito (2010) assim o reconheceu, o futebol é uma linguagem e o jogo um drama. Esmerando-se em destacar que não se trata de distinção valorativa, Pasolini elenca uma tipologia de formas de jogo e atores, destacando as dimensões instrumental e expressiva da linguagem, e modulando os exemplos para poder até mesmo sugerir uma prosa poética, como no caso de Altafini Mazzola, campeão mundial pelo Brasil em 1958, depois emigrado, como argentinos e uruguaios, chegando a jogar pela Itália na Copa do Chile, em 1962.

"A retranca e a triangulação é futebol de prosa: baseia-se na sintaxe, isto é, no jogo coletivo e organizado, na execução racional do código", diz Pasolini (2005, s.p.), com o qual ecoa Negri ([2006]), que afirma que "nós que somos de Pádua, ligados em velha aliança com o Milan, somos os inventores do catenaccio [parafuso]. E o catenaccio é a grande construção do operário-massa". Mas, diz Pasolini (2005, s.p.), "Se o drible e o gol são o momento individualistapoético do futebol, o futebol brasileiro é, portanto, um futebol de poesia. Sem fazer distinção de valor, mas em sentido puramente técnico, no México [em 1970] a prosa estetizante italiana foi batida pela poesia brasileira". Ou seja, é por contraste, também, que o futebol europeu pode representar-se e, com ele, colocar a Europa não exatamente como território, mas como projeto cultural.

Em tão breve quanto contundente texto, Claussen (2014a) afirma que a Europa teria nascido numa quarta-feira, no embrião do que conhecemos como Liga dos Campeões, torneio que começa como Copa dos Campeões da Europa que, por sua vez, se inspirara na Copa da Europa Central ${ }^{7}$, jogada nos anos 1920 e 1930, nos primeiros passos do movimento de profissionalização do futebol, com destaque para equipes austro-húngaras. Jogava-se às quartas-feiras - hoje de terça a quinta em mais de uma competição europeia - porque os finais de semana seguiam reservados aos torneios nacionais.

Foram dois os movimentos-chave para que esse quadro se estabelecesse, ademais dos interesses econômicos vinculados ao espetáculo esportivo que se deixava desfrutar, paulatinamente, não mais apenas pelo rádio, mas também, aos poucos, pela televisão. Ambos têm a ver com a circulação de jogadores pelo continente. Em dezembro de 1956, o Budapest Honved, time de grande prestígio ligado às forças armadas da Hungria, joga com o Atlético

\footnotetext{
6 Mas também da margem esquerda, como os uruguaios Juan Alberto Schiaffino Villano e Alcides Ghiggia, autores dos gols que derrotaram a seleção brasileira na final de 1950. Além disso, como mostram Rigo e Torrano (2013), em especial no que se refere ao Barcelona FC, jogadores de outras nacionalidades sul-americanas, e de outros continentes, também migram para a Europa.

7 Hobsbawm (1992) também aponta a Mitropa Cup como um evento importante no combate esportivo entre nações, demarcando-o como espetáculo importante no período entreguerras, com realce para as pelejas entre Áustria e Hungria - o futebol do Danúbio, como o nomeia Antonio Negri. Hobsbawm se recorda de escutar pelo rádio uma partida de futebol entre Inglaterra e Áustria, com seus primos, no final dos anos 1920 .
} 
de Bilbao, pela Copa dos Campeões da Europa, em Bruxelas. Numa noite de quinta-feira, empatam em três gols, e a maior parte de seus jogadores não retorna ao país conflagrado pela reação soviética à revolução popular. Puskas, Cocsis, Czibor e outros astros encontram trabalho no Oeste, tornando-se, com o tempo, ídolos dos dois lados daquela Europa dividida. O segundo movimento teria sido a migração de outros jogadores internamente ao continente europeu, notadamente alemães a clubes da Itália, afastando-se de um profissionalismo que era ainda incipiente e clandestino no país de origem (CLAUSSEN, 2014a).

A circulação de jogadores aliada e fomentada pelo espetáculo esportivo - que fez com que se deslocasse a torcida apenas nacional para outros times, de outros países, cada um tendo um segundo e até terceiro clube de predileção - ajudaram, escreve Claussen (2014a), a conformar uma comunidade imaginada, nos termos propostos por Benedict Anderson (1991). De fato, para Anderson, os termos de uma comunidade imaginada estão postos para a Europa, em especial no que se relaciona às fronteiras que a abarcariam e ao conteúdo cultural compartilhado, neste caso, o futebol. Mais que isso, a própria designação da comunidade imaginada vem, de certa forma, de fora:

As equipes de ponta transnacionais - como as chamariam hoje os cientistas sociais - foram suplantadas pelo Benfica. A estrela do time era um certo Eusébio, que em Moçambique crescera em um time de futebol de rua chamado Os Brasileiros. A Copa da Europa trouxe o mundo para a Europa e com a televisão levou-o a cada sala de estar. A Europa hoje não consiste apenas na Champions League; mas a antiga Copa das Cidades-Feira (Messestädtepokal) e a UEFA-Cup se tornaram a Liga Europeia, que oferece um objetivo possível para equipes menores do continente (CLAUSSEN, 2014a, s.p.). ${ }^{8}$

Sim, o Benfica FC, treinado por Béla Guttmann, o mago húngaro que mandou contratar Eusébio, com o qual levou o clube português ao bicampeonato europeu em 1961 e 1962. Nesta última ocasião, ao abater o poderosíssimo e multinacional Real Madrid de Puskas, Di Stéfano e Gento em Amsterdam, um gandulo que se tornaria muito especial poucos anos depois pôde assistir ao time português e seu esquema tático bem-elaborado, em que despontava o genial atacante moçambicano de cidadania portuguesa. Johan Cruyff, então jogador das categorias de base do Ajax Amsterdam, filho de uma encarregada da limpeza e morador das circunvizinhanças proletárias da sede do clube, tornar-se-ia, ele mesmo, um catalizador dessa comunidade imaginada que é a Europa pensada e materializada pelo futebol.

Parece que os círculos vão se fechando. Na temporada de 1971-1972 o Ajax, treinado pelo romeno Stefan Kovács, foi o vencedor da Copa dos Campeões da Europa contra a Internazionale, em Roterdã, depois de vencer Dynamo Dresden na estreia e o Benfica na semifinal. Na temporada anterior a vítima havia sido o Panathinaikos, em Wembley, dirigido nada menos que por Ferenc Puskás, o astro húngaro refugiado que despontaria no Real Madrid. O Ajax ainda era comandado por Rinus Michels, que logo transferiu-se para o Barcelona, começando a longa e profícua relação entre holandeses e catalães. Cruyff foi o maestro desses

8 Perguntado por Nuno Madureira sobre a presença de refugiados na Alemanha, em particular em relação à onda recente, e o futebol, Claussen $(2015$, s.p.) respondeu que "Hesito muito em usar o conceito de identidade. Até ao fim do século XX era efetivamente possível identificar no futebol estilos nacionais diferentes - mas digo isto de forma prudente, cum grano salis. Todas as seleções de sucesso tiveram processos semelhantes de modernização - por exemplo, enquanto o Brasil trabalhou a disciplina, a Alemanha tornou-se mais técnica [tecnicista, na tradução original]. Por outro lado, esse estilo refletia o que era praticado nas principais Ligas, mas aí também havia diferenças regionais. Nos últimos 20 anos, sob pressão de interesses económicos, passaram a identificar-se três grandes arenas de futebol de sucesso: a Champions League, a Premier League e as competições internacionais de seleções".

Jogadores de outros países são chamados, eventualmente, de legionários (Legionäre). Há dois anos, em partida entre o Union Berlin e 0 Bochum, pela segunda divisão alemã, o programa do jogo anunciava nove no plantel do anfitrião, vindos de sete nações diferentes, o mesmo número do adversário, mas este com uma nacionalidade a mais (1 FC UNION BERLIN gegen VfL BOCHUM - Program, 29/04/2016.). 
confrontos do multicampeão Ajax e seu futebol total, base do Carrossel Holandês que deliciaria o mundo no ano seguinte, mesmo perdendo a Copa, aliando habilidade, técnica, estrutura tática e condição física. Para Negri (2007, s.p.),

[...] Por outro lado, o jogo total holandês é a transição para o social, o início do cognitivo. Aqui estão os esplêndidos holandeses que giram, giram, até o ponto em que não podem mais ser encontrados: não havia um zagueiro, um ala, um centroavante. Todo mundo, em todos os lados, a todo momento. Os esquemas do futebol total, as novas geometrias em que singularidade e conjunto podiam funcionar.

Em 1973, a final da Copa dos Campeões da Europa fez oporem-se o Ajax, em busca do tricampeonato e a Juventus de Turim, em Belgrado, Sérvia, então capital da lugoslávia não alinhada do Marechal Tito. O Ajax envolve a Juve, em que joga o já veterano Altafini Mazzola, sim, o campeão do mundo em 1958 pelo Brasil e depois astro em equipes italianas e na seleção daquele país na Copa de 1962. Em plena Guerra Fria, duas equipes ocidentais se encontram no estádio do Estrela Vermelha, chamado Marakana, o mesmo que anos depois seria palco da batalha campal entre torcedores, policiais e jogadores em um clássico contra o Dínamo Zagreb, em 1990 e ainda, durante a Guerra da Bósnia Herzegovina, sede de apoiadores de Slobodan Milosevic. O Ajax venceu, conquistou o tricampeonato, frente a cem mil pessoas. Segundo se escreveu na época (AQUINO; ARAÚJO, 1973), holandeses e italianos (em franca maioria), tomaram as ruas e bares para amigavelmente celebrar o futebol.

\title{
4 COMUNIDADE IMAGINADA
}

\author{
Escreve Eric Hobsbawm (2007, s.p.), que
}

O futebol sintetiza muito bem a dialética entre identidade nacional, globalização e xenofobia dos dias de hoje. Os clubes viraram entidades transnacionais, empreendimentos globais. Mas, paradoxalmente, o que faz o futebol popular continua sendo, antes de tudo, a fidelidade local de um grupo de torcedores para com uma equipe. E, ainda, o que faz dos campeonatos mundiais algo interessante é o fato de que podemos ver países em competição. Por isso acho que o futebol carrega o conflito essencial da globalização.

A comunidade imaginada europeia por meio do futebol é principalmente, no entanto, a dos clubes, principalmente depois da II Guerra, e, é preciso não esquecer, de migrantes. Diz Antonio Negri (2006) que os franceses estão por toda parte enriquecendo o "maquiavelismo" do futebol italiano com sua "razão de estado". A composição faz valer a rivalidade entre times e cidades, muito mais marcante em um país como a Itália, de unificação tardia, mas por toda a Europa. Se a "Europa se tornou um centro de gravitação do futebol mundial - todos querem estar presentes no meio de semana, nem que seja frente à televisão" (CLAUSSEN 2014a, s.p.), é porque os clubes podem corporificar a comunidade imaginada em torno do futebol, do continente, de uma cultura.

Se é possível dizer que o futebol na Europa ajudou, como cultura urbana e popular, na construção de uma esfera pública proletária - em complemento e contraposição à burguesa -, se admitimos a proposição de Negt e Kluge (1972), é também preciso reconhecer seu crescente processo de gentrificação associado ao puro fetichismo de espetáculo esvaziado de radicação social. Ou uma forma de "entretenimento repressivo", como o classificou Negt (2012), ao se 
referir à Copa da Europa de 2012 e a certo recrudescimento do nacionalismo associado a ela. Mas não é só isso. Afinal,

[...] como a cultura, o futebol é uma 'mercadoria paradoxal'. Se os bens culturais da sociedade burguesa do século dezenove não houvessem se transformado em mercadoria, os artistas nunca teriam se emancipado da tutela aristocrática, assim como jamais teria sido possivel sequer imaginar a arte autônoma. Sem a profissionalização do futebol, não haveria possibilidade real para proletários, migrantes e outsiders participarem, de forma ampla, da vida pública (CLAUSSEN, 2012, s.p.).

Cultura da classe trabalhadora, masculina (hoje muito também feminina), esta tradição inventada da qual nos fala Hobsbawm (1983, p. 301) teria a força de se apresentar "independente das diferenças locais e regionais". Com ela, encontramos, neste curto-circuito que procurei montar aqui, personagens circulantes entre nações que se constroem e deixam de existir, migrantes e expatriados que compõem e recompõem os Estados-Nação, cada país, mas, mais do que isso, uma cultura viva europeia. Como queria Thomas Mann, uma Europa não dominada por um país, língua ou sotaque, mas por uma renovada tradição comum.

\section{REFERÊNCIAS}

1 FC UNION BERLIN gegen VfL BOCHUM - Program, 29/04/2016.

ADORNO, Theodor W. Minima Moralia: reflexões sobre a vida danificada. Tradução de Luiz Eduardo Bicca. São Paulo, Ática, 1992.

ADORNO, Theodor W. Das Schema der Massenkultur. Gesammelte Schriften 3. Frankfurt am Main: Suhrkamp, 1997a, p. 299-335.

ADORNO, Theodor W. Meinung, Wahn und Gesellschaft. Gesammelte Schriften 10-2. Frankfurt am Main: Suhrkamp, 1997b. p. 573-594.

ANDERSON, Benedict. Imagined communities: Reflections on the origin and spread of nationalism. London: Verso, 1991.

AQUINO, José Maria de; ARAÚJO, Zeca. Nunca foi tão fácil. Placar, n. 168, 08 jun.1973, p. 2831.

CLAUSSEN, Detlev. Wo waren Sie, als das Sparwasser-Tor fiel? Jungle World, 11 set.1997. Disponível em: <https://www.jungle.world/artikel/1997/37/wo-waren-sie-als-das-sparwasser-tor-fiel>. Acesso em: 10 dez. 2018.

CLAUSSEN, Detlev. Fortgesetzter Versuch, das Endspiel zu verstehen. In: HEFELE, Albert; ROTH, Jürgen. Alle meine Endspiele. Herrliche Fußballgeschichten - von Bern bis Hamborn. Berlim: Tiamat, 1998. p. 45-51. (Critica Diabolis78).

CLAUSSEN, Detlev. O clube de Oskar. Contemporânea: uma quase revista, n. 1, jul. 2012. Disponível em: <http://pt.slideshare.net/badlila/contempornea-01>. Acesso em: 10 dez. 2018.

CLAUSSEN, Detlev. Europa wurde an einem Mittwoch geboren. Eutopia. Ideas for Europe Magazine, n. 1, 09 apr. 2014a. 
CLAUSSEN, Detlev. Noch immer aktuell - von Sisi bis Balotelli. [entrevista cedida a] Lukas Wiselberg. Science.Orf.at, 31 jan. 2014b). Disponível em: <https://sciencev2.orf.at/ stories/1732633/index.html>. Acesso em: 10 dez. 2018.

CLAUSSEN, Detlev. Béla Guttmann: uma lenda do futebol no século XX. Tradução de Daniel Martinsechen e Alexandre Fernandez Vaz. São Paulo: Estação Liberdade, 2014c.

CLAUSSEN, Detlev. Os que estão a chegar darão um contributo importante ao desporto. [Entrevista a] Nuno Madureira. Mais futebol, 13 out. 2015. Disponível em: < http://www. maisfutebol.iol.pt/refugiados/entrevista/os-que-estao-a-chegar-darao-um-contributo-importante-aodesporto>. Acesso em: 10 dez. 2018.

ECO, Umberto. II calcio secondo Eco: dal Grande Torino alla cultura della chiacchiera. [entrevista concedida a] Vittorio Sermonti. La Reppublica, RepublicaSport, 9 jul. 1982. Disponível em: <http://carotenuto.blogautore.repubblica.it/2016/02/20/il-calcio-secondo-eco-dalgrande-torino-alla-cultura-della-chiacchiera/?refresh ce >. Acesso em: 10 dez. 2018.

ECO, Umberto. La estrategia de la ilusión. Barcelona: Penguin 2015.

ESPOSITO, Roberto. Pensiero Vivente. Origine e attualità della filosofi a italiana. Torino: Einaudi, 2010.

GUMBRECHT, Hans Ulrich. Wie der Sport inspiriert. TAZ, 30-31 jan. 2016, p. 39.

HOBSBAWM, Eric. Mass-Producing Traditions: Europe, 1870-1914. In: HOBSBAWM, Eric; RANGER, Terence (Org.). The Invention of Tradition. Cambridge, Cambridge University, 1983.

HOBSBAWM, Eric. Nations and Nationalism since 1780. 2nd. ed. Cambridge, Cambridge University, 1992.

HOBSBAWM, Eric. Futebol hoje sintetiza a globalização. [Entrevista a] Sylvia Colombo. Folha de São Paulo, São Paulo, 30 set. 2007. Disponível em: <http://www1.folha.uol.com.br/fsp/mundo/ ft3009200708.htm>. Acesso em: 10 dez. 2018.

HOBSBAWN, Eric. Age of Extremes: The Short Twentieth Century 1914-1991. London: Abacus, 1997.

HORKHEIMER, Max; ADORNO, Dialektik der Aufklärung. Philosophische Fragmente. Frankfurt am Main: Suhrkamp, 1997. (Gesammelte Schriften, 3).

KLUGE, Volker. Das Sportbuch DDR. Berlim: Eulenspiegel, 2004.

MANN, Thomas. Ansprache vor Hamburger Studenten. In: Gesammelte Werke in XIII Bänden. Band XIII. Frankfurt am Main: Fischer, 1974.

NEGRI, Antonio. Calcio e lotta di classe. Un'intervista a Toni Negri. Supereva. No Global, [2006]. Disponível em: <http://guide.supereva.it/no global/interventi/2006/06/259471.shtml>. Acesso em 06 abr. 2016.

NEGRI, Antonio. "Gli ultrà dell'iperumano". Intervista a Toni Negri. 17.11.2007. Miccia corta. Uma storia di Prima linea. Acesso em: 06 abr. 2016. 
NEGT, Oskar. Die Risse des Systems aufdecken. [Entrevista a] Von Ingo Anhenn e Wilfried Voigt, [Fotos de] Martin Storz. Kontext. Wochenzeitung, n. 64, 20 jun.2012. Disponível em: $<$ http://www.kontextwochenzeitung.de/debatte/64/die-risse-des-systems-aufdecken-826.html>. Acesso em: 25 abr. 2016.

NEGT, Oskar; KLUGE, Alexander. Öffentlichkeit und Erfahrung. Zur Organisationsanalyse von bürgerlicher und proletarischer Öffentlichkeit. Frankfurt am Main: Suhrkamp, 1972.

PASOLINI, Pier Paolo. O gol fatal. Tradução de Maurício Santana Dias. Folha de São Paulo. São Paulo, 06 mar. 2005. Caderno Mais. Disponível em: <http://www1.folha.uol.com.br/fsp/mais/ fs0603200506.htm>. Acesso em: 10 dez. 2018.

REDEKER, Robert. Ansteckung der Seelen. Tradução para o alemão de Rudolf Balmer.TAZ, 16-17 jan. 2016, p. 39.

RIGO, Luiz Carlos; TORRANO, C. Identidades dos clubes de futebol: singularidades do FC Barcelona. Movimento, v. 19, n. 3, p. 191-210, jul./set.2013.

ROTH, Philip. Shop Talk: A Writer and His Colleagues and Their Work. London: Vintage, 2002.

Nota:

Uma primeira versão deste texto foi apresentada no Centro de Estudos Europeus da Universidade Federal de Minas Gerais por ocasião do Workshop Europa: prefigurações de um espaço comum. Meu agradecimento à Myriam Ávila pelo convite e pela hospitalidade. Agradeço ainda a Michelle Carreirão Gonçalves e a Lisandra Invernizzi pelas críticas à versão anterior do texto, assim como aos revisores da Movimento. O trabalho é resultado parcial do Programa de Pesquisas Teoria Crítica, Racionalidades de Educação (V), financiado pelo CNPq (apoio à pesquisa, bolsas de iniciação científica e pesquisador 1C). 